\title{
Knowledge and Instruments Cultural Modern in the Everyday Practices of Making Environmental and Labor Education
}

\author{
Dirlêi Andrade Bonfim ${ }^{1, *}$, Milton Ferreira da Silva Júnior ${ }^{2}$ \\ ${ }^{1}$ Faculdade Independente do Nordeste, Vitória da Conquista, Bahia, Brazil \\ 2Universidade federal do Sul da Bahia, Ilhéus, Brazil \\ *Corresponding author: dirleibonfim@gmail.com
}

\begin{abstract}
The present article seeks to articulate some thoughts about environmental issues, about the knowledge of the integration of knowledge and instruments of cultural modern in the everyday practices of labor and make education. In this process, we realize many times that the educational Institutions and training such as the construction organising and articuladoras of knowledge that enable the exchange of concepts, ideas, values and construction of the science, comes in the course of time promoting the encounter between the educator and the learner and between the object of knowledge and the object of education. Presents a discussion on Environmental Education in Brazil, whose analysis of the data, if processed by the method cartographic proposed as path wandering. Thus, the present work has the objective of raising the discussion about the environmental doing in the universe of daily practices of the educational work and to bring to the fore the subjects of education in the broader sense, the plural subject. For that, it was used the revision of the scientific literature with the perspective of bringing to the discussion a look of the knowledge and cultural instruments. It is therefore part of an essentially dynamic educational process that can foster and promote transformation at the same time, within a continuous universe of relevant metamorphoses. That imposes on us all taken positions and at the same time the necessity of not only observing such changes but somehow inserting themselves in that process.
\end{abstract}

Keywords: cultural knowledge, environmental education, daily practices, plural subject format, microsoft

Cite This Article: Dirlêi Andrade Bonfim, and Milton Ferreira da Silva Júnior, "Knowledge and Instruments Cultural Modern in the Everyday Practices of Making Environmental and Labor Education." American Journal of Educational Research, vol. 5, no. 7 (2017): 756-761. doi: 10.12691/education-5-7-10.

\section{Introduction}

In the course of its history, the human being has built an educational process, in the daily tasks and labors that are part of his existence, which constitutes him, which instigates him, what he desires or what he needs, as an indispensable condition for his own survival. The human being who is distinguished by what is unique to him, is also characterized by the similarities he has with other human beings. In this paradox of singularities in the diversity and in the indispensable condition of the relation with himself, with his peers, with other forms of life and with nature, that man is humanized and dehumanized. It is in a constant process of mutation and modifies the world characterized by its rationality and historicity. It has the logos (interprets, denounces, announces, argues, abstracts, knows) and is born marked by the historicity that manifests as praxis. In acting and making human knowledge was a fundamental element. There is a relational dimension between human knowledge and know-how.

Thus, education must provide in an intense and effective way, more and more knowledge and evolutionary know-how, which projects the human animal in the construction of the theoretical, literary, scientific and technological possibilities of the future. It is also incumbent upon him to point out references that prevent people from being submerged in waves of information, sometimes ephemeral, providing instru-ments for a better understanding of the complex and constantly agitated world. Without losing the conceptions of forms that develop, simultaneously reason, sensation, feeling and intuition, as stimuli for multicultural, interdisciplinary and contemporary integration on the world.

Developing the educational process (teaching and learning), contemplating both scientific knowledge and the sensitive aspects of life (social representations, human/nature relation etc.) means working with the identity and social environment.

The practice of interdependence is an interdisciplinary pedagogical practice that is effective in the knowledge of integration. According to Fazenda, it characterizes interdisciplinarity by the intensity of the exchanges between the specialists and the integration of the disciplines in the same research project ... In terms of interdisciplinarity there would be a relation of reciprocity, mutuality or, better A system of co-ownership and interaction that will enable dialogue between stakeholders. Interdisciplinarity then depends, basically, on a change of 
attitude towards the problem of knowledge, from the replacement of a fragmentary conception with the unitary one of the human being. [1]

Still if we define Interdisciplinarity as junction of disciplines, it is possible to think curriculum only in the formatting of its grid. [2] However, if we define Interdisciplinarity as an attitude of daring and search for knowledge, it is appropriate to think about aspects that involve the culture of the place where teachers are formed.

Thus, insofar as we extend the analysis of the conceptual field of Interdisciplinarity, the possibility of an explicitation of its epistemological and praxeological spectrum arises. Only then, it becomes possible to talk about the teacher and his training, and thus with regard to disciplines and curricula. We come to the question: how is Interdisciplinarity defined when the intention is to train teachers?

\section{Doing Everyday Education}

Any form of education that does not bring "certainties" but reaffirms the creative potential of the human being to build a "new" path, walking through it. It is necessary, therefore, to respect unity in diversity without imposing a single truth on the meaning and meaning of human existence. Nothing is, everything can be: the search for a new frame of reference.

To build their story humans have elaborated several readings of reality. It was based on a hegemonic cultural model that marked(a) a certain historical moment. Different visions of the world follow each other, changing the definitions of its components, announcing a "new" world, provoking resistance and at the same time an awareness of a propitious moment for a profound reformulation in scientific conceptions. Opportunity for changes, qualitative leap in the evolutionary process of science, perhaps, prelude to a new paradigm.

In a historical attempt to know the world to better understand it, it resulted in the fragmentation of the knowledge used by human beings as a foundation in the management of their relations with the world. These principles have been reflected in the planning and implementation of human activities, most often immediate and localized, almost always without any historical, prospective or environmental consideration. They are priorities defined by immediacy, individualism or corporatism, regardless of the spatial and temporal environment. The principles have guided individuals' attitudes and mutually reinforcing social relations, serving as a basis for the formulation of development models of human societies, [3] and has prevented full understanding of the complex levels of organization and Interdependence of the components of our universe.

With the almost always immediate valorization, that of crisis of utopias and the deconstruction of the subject, they can, however, configure themselves as important elements for reflection on the responsibilities of old and new social, cultural, economic and environmental problems. It is necessary to discuss both the environmental problem and the ethics of human endeavors, the labor market, inequalities, exclusion, inclusion, suffering, pleasure, consideration for the other, elements that cross the political, cultural, economic and Educative, provoking the resizing of our practices, styles, beliefs, habits, customs, and the possibility of building new development styles for human societies.

According to Foucault, this empirical and growing representation of the population Reverses its importance in society. The family, which used to be the target of the state, loses its place to the population. However, the family continues to be important, but as part of the population. The ruler to reach the family must first pass through the population. Before, the art of governing and the economy were only thought from the model of family organization. In other words, along with the concept of population, the family becomes a secondary element; Becomes a sphere of the population, later a group, losing the status of state model.

If we seek the middle ground or the point of passage for this modern demand, we will see that mercantilism is paradoxical in the Market-State relationship. If, on the one hand, mercantilism, as a market practice, made clear rules for commercialization on a world or transcontinental scale, created laws for this market and a regularity being administered within the State; On the other hand, served as support to the sovereign to increasingly arm themselves, creating armies and armaments, keeping him in power.

"The art of governing sought to be based on the general form of Sovereignty, while at the same time being able to To rely on the concrete family model; For this reason, she was blocked by this idea of economy, which at this time Still referred to only a small set consisting of by the family and by the house. With the State and the sovereign of a side, with the father of the family and his house of another, the government could not find its own dimension". [4]

The population is for this reason the purpose of government. The art of governing reaffirms itself between: individuality (consciousness of the man who is part of the population) and the general interest that is the need or will of the population as a whole. The change of government model leads to the need to think about the relationship between the State and the population. "The idea of a new government of the population makes the problem of the foundation of sovereignty even more acute, and even more acute is the need to develop discipline." [4] The population is also a source of power. In the exercise of central power comes a concern: how to discipline these innumerable powers that spring, above all, from the population? In short, it is a problem contemporary to the complexity of the population in the constitution of a State. "It is a triangle: sovereignty - discipline - government management, which has in the population its main target and in security devices its essential mechanisms". [4] In which sovereignty must be maintained; Guarantee the exercise of power that is now multiple through discipline, disciplining power and hierarchizing it to administer in a technical way, using all the mechanisms that society has to make effective government action.

Nor the transcendent power, given by a powerful extramundane being. It is a human, concrete, real, and multiple power that extends throughout the social structure. 


\section{Cartography and Educational Knowledge}

The mapping of knowledge is a methodological approach marked by cultural hybridity, which implies a new ethics of convergent and conscious science. In an approach that has materialized between frontiers of multi-intertransdisciplinary knowledge, and has emerged as an intercultural research praxis, an investigative path to account for inter-multiculturalism.

Cartography has as its main source of inspiration the information that the eye Can capture and record. This means that perception can be seen As a step prior to cartographic representation. Without perception there will be no representation. Therefore, the way of seeing is a human construction. In the case of Modern cartography, the basis of observations is the geometric view of the Reality artificially created from the principles of Renaissance perspectivism.

We understand the environmental cartography, intricate within the thematic cartography, with some specifications and different applications. A cartography, in turn, attached to a specific sector of thematic cartography responsible for the systematization of environmental maps or the environment.

The graphical representation of the environment is embedded in the configuration of the earth's surface and how it is being represented by man, as well as the need to emphasize landscapes and places occupied by man's activities.

When we deal with environmental graphics, we are referring to technique and art. We use the word representation in its broadest meaning, as an expression of reality: a map with this connotation best represents what is known of the Earth, what can be seen from the highest points. We see the confrontation in this definition of two visions: technique with all its conventionalism and art with all its abstraction.

Hence the suggestion of Cartography as a research method proposed by Deleuze and Guattari [5], as Kastrup [6] explains, for the study of the procedural dimension of subjectivity and its production process. The conceptual appropriation of the cartography that is based mainly on the philosophy of Gilles Deleuze and Felix Guattari, in the book Mil plateaus: "Cartography (as a methodological strategy) seems to create inflections according to the multiple terrains that the researcher finds, unfolding through spheres and paths that offer material for the production of different senses and compositions". [5]

In Deleuze [7], it comes to bring some components for cartography, notions of space, social human maps, multiplicity, territoriality and temporality, such as are constituted, before the concept of duration: permanent changes in which are the differences of nature .

Cartography has as its main source of inspiration the information that the eye Can capture and record. This means that perception can be seen As a step prior to cartographic representation. Without perception there will be no representation. Therefore, the way of seeing is a human construction. In the case of Modern cartography, the basis of observations is the geometric view of the Reality created artificially from the principles of perspectivism Renaissance.
Cartography, according to Kastrup [6], is a method proposed by Deleuze and Guattari [5] that has been used in research interested in the study of subjectivity. It is about investigating a production process, of following a certain unusual path, a certain time that lasts. Thus, cartography occupies itself with a moving plane, interested in the metamorphoses and anamorphoses taken as processes of differentiation.

Configuring itself as a method whose definition of steps a priori is put under suspicion, its doing is done by des (work), by a kind of disposition of (un) ready, in order to tune with the procedural paths that are Constitute their object. How to do it, but adopting an intuitive posture?

However, just as intuition as a method presents itself as a rigorous philosophical procedure, cartography also requires rigorous researcher care. Instead of constituting a task that assumes an air of total independence of principles, one must instead pay close attention to certain elements that serve the cartographer of "fleeting-solid stones on the road" where he can step on Nomad mode. Otherwise, it may be captured by the forces of intelligence that tend to hasten to fix and order the unfixed and inordinate dimensions of the field of research.

How to do it, then? Kastrup [6] points out what would be eight tracks of the cartographer: it is a method to follow processes and not represent objects; Refers to a collective of forces, aims at an existential territory; Traces a troublesome field; Requires the dissolution of the observer's point of view; Requires a certain kind of attention to the present; Requires devices to function; And, finally, it consists of a method that does not separate intervention research.

From them, we extract three to discuss in this text: their occupation with the tracing of a problematic field, the dissolution of the observer's point of view and the specific attention to the present. We do this because it seems to us that these are linked in a special way to our purpose: to think the cognitive work of the researcher who uses cartography and that of the cognitive work is impregnated. And also, for instigating us to raise some questions regarding the place of imagination and fable in the enterprise of cartographic research.

To map a problematic field as a cartographer means to problematize the cognitive forms of the researcher himself in his relation to the field to which he is dedicated. Thus, it requires a permanent modulation of the problem, a posture of openness to the forces that force one to think, as attuned to the dimension of the first rule of intuitive method: reconciling truth and creation at the level of problems.

Such a clue points to the importance that in research the researcher should be guided in the direction of inventive resolutions, which force him to trace new problems in an incessant nonconformity that allows him not to yield to the seductions of the appeasement responses linked to the plane of recognition. Instead, it produces vitality to the forces that give existence to things, producing research material at the very moment when it problematizes the field.

When it is said that the clarity which arises from intuition is somewhat obscure because it refers to a radically new idea. These are radically new ideas both in relation to the field and the researcher, in a process in 
which, by a zone of contact, both leave, in a way, to be what they are. Such dissolution marks the force that leaves the dichotomy of the subject-object pair, instituting a process of double capture in which researcher and field are done in an implied-explained movement.

The implication, an inevitable tool in the cartographer's work, highlights the nature of the subject-object relationship as characteristic of a transductive relationship, in an allusion to the concept of transduction. [8] To speak in a transductive relation is to refer to a relation established in a zone of non-forms, therefore, in the case of non-subject forms and object that, interpenetrating themselves, create a field of mutual and moving fertilization.

The environmental theme has aroused great interest in various segments of society. However, the bibliography produced for Social and Environmental Cartography has presented gaps, mainly in the treatment of the base of research with a theoretical-methodological approach.

As for the productions of this line of research, Jean Tricart can be highlighted for the environmental mapping. Environmental cartography deals with the interaction between socioenvironmental conditions and cartographic science, which is the very interface between the first two, exposing, within a historical context, several visions of the relationship between society and nature. Thus, cartography, as a means of analysis, can contribute in a profound way to environmental research, seeking to reflect on this theme and help in the formation of visions and increasingly critical actions between the society-space relationship.

Cartography in the socio-environmental context aims to measure the relations between society and the environment and their implications, being possible through the survey of social and natural conditions and, later, the graphical representation of these relations considering the interaction between knowledge Scientific and popular wisdom.

Therefore, the development of this line of research is of fundamental importance for society, since it comes to reveal the elements and phenomena of nature and their respective relationships. Descriptions and graphical representations reorder the information by expressing more abstract varieties, broadening the understanding and management of space and its components.

In this way, reading the world goes far beyond cartographic reading, whose representations reflect the territorial realities, sometimes distorted by the cartographic projections adopted. Reading the world is not just reading the map, or the map, although it is very important. It is to read the world of life, constructed daily and that expresses both our utopias and the limits that are placed on us, be they within the scope of nature, or the scope of society (cultural, political, economic). [9]

Thus, in the development of activities with learners, Cartography is not used as a single element, but as an important visual resource to explore the lived space and teaching of environmental education. According to this perspective, "in the school context, the various curricular components, especially the contents of the Cartography, provide the necessary subsidies for the expansion of the students' knowledge about the place where they live and work". [9]

Cartography represents an important resource for the educational process, especially in the recording of representations of conflicts between the various actors involved in this context, because it allows the representation of the different space cuts and in the scale that is appropriate for teaching. In this way, Cartography enables teachers and students to understand the way they are inserted in space, which can be local, regional and global. Through maps, be territorial, mental, sentimental and or marginal, arranged through the various representations.

Environmental cartography should explore the two semiological systems together: polysemic and monosemic, the polysemic being dealing with multiple meanings, such as those of figurative language, while monosemics deals with the single meaning, such as mathematical language and graphic representation, Like the map. Environmental cartography also works with multiscales, photographs, diagram blocks, drawings, among other graphic representations.

Environmental cartography is born in a similar way to the first thematic maps, those that were constituted through the addition of specific elements of the environment, mainly as point manifestations in topographic cartography. In this way such maps do not arrive at a more elaborate construction on categories of the environmental theme, but only demonstrate a visual organization, confirming the cartographic tradition of describing the visible world. We can not speak of a proper system of graphical representation of the environment, with own signs thought and rethought for the environmental phenomenon.

We must emphasize environmental cartography belonging to a very specific context - that of graphic representation - within visual communication.

The two semiological systems interact when the image of the place (what attracts the individuals) and the map of the place (new motivating factor) interact for the decision of choice and domination of the place chosen for the environmental action (be it hiking, scientific exploration) Which is why environmental cartography should use the two semiological systems, as complements and not as antagonisms.

The graphical representation due to its complexity has, over time, improved on the image of the natural references and the accuracy of the location of the main environmental phenomena. However, we have not been able to apprehend its evolution in terms of visualization, since the number of information is still scarce and we have difficulty following the development of this branch of thematic cartography. The fact is that we must pay attention to the harmonization of knowledge in the establishments of the connections between the Sciences and the disposition within the process of interdisciplinarity, as a form of greater comprehension and comprehension of the facts, in this practical-theoretical relation, in the construction of conceptual bases that can Better explain the scientific developments to ordinary people.

In this aspect, for Japiassu [10], the discourse that knowledge is the fundamental basis of civilization is insufficient, at least incomprehensible to the student who ends up being oblivious to the so-called classical knowledge. In history teaching we can cite serious failures of the most Common today, for example: the fact of explaining the present by the past in a practice of simple exposition of facts, ends up not putting the student as constructor of history; Or the very fought, by the academy, 
a practice of heroes' history that is still usual in elementary and middle school, which diminishes the student before history, giving him a pantheon of heroes practically mythical. This occurring in depreciation of a conjuncture analysis or social practices that could appear as something more tangible to the students and, even with the differences of time, the student would be able to identify signs that would be common to him and to contrast the differences. The interdisciplinary practices tend to, as already said, seek a unitary knowledge, where the integration of all the disciplines and their connection with the reality of the student make the knowledge real and attractive, and sometimes the student can see it as essential.

"The legal formalism of an abstract theory, detached from any reference to Real life, can lead to the worst absurdities, thus betraying the very essence of legal function. Similarly, the rigorous formalism of this or that scientific theory may develop, under deceptive Perfect accuracy, ignorance of the near and distant implications. Of human existence". [10]

Thus captivated by the detail, the specialist loses the meaning of the set, not knowing more about him. [10]

We thus have the integration of various disciplines, working "together" for some period. It is undeniable that such a strategy can be successful in the classroom, after all it shows the students a practical application of the hitherto intangible knowledge. But such a pedagogical proposal can not be confused with an interdisciplinary attitude. What usually happens is that the disciplines are only using the common theme as a practical example of their closed universe, not creating a relationship with the other disciplines. So we come to the old Chinese adage: "A house is made of a handful of bricks, but a handful of bricks is not a house."

\section{Work and Environmental making}

In the process of building a sustainable education, one is talking not only of one kind of knowledge. Environmental Education, in turn, talks about social representation, for the conquest of citizenship. It does not refer only to the environment as many people think; Today, implies the attempt to change the anthropocentric thought of man to show that he is part of nature and therefore has to obey ecological principles and diversity. It is necessary that in the educational media can be incorporated the diversity of social policies and practices as a subsidy in the learning teaching process, stimulating teachers and students to the commitment and ethical sense to ecological practices aimed at environmental preservation, as well as the awakening to very simple things that can be done to reduce the impact to the environment through practical attitudes towards the three R's of conscious consumption are: reduce, reuse and recycle.

The relationship between the environment and education for citizenship assumes an increasingly challenging role, demanding the emergence of new

Seize complex social processes and intensify environmental risks.

Environmental policies and educational programs related to the awareness of the environmental crisis are increasingly demanding new approaches integrating a contradictory and inequitable reality that transcends the mere application of available scientific and technological knowledge.

The challenge is therefore to formulate environmental education that is critical and Innovative, at two levels: formal and non-formal. Thus, environmental education must

Be above all a political act aimed at social transformation. His approach must seek a holistic perspective of action, which relates man, nature and the universe, taking into account that natural resources are exhausted and that the main responsibility for its degradation is man.

For Sorrentino [11], the major challenges for environmental educators are, on the one hand, the recovery and development of values and behaviors (trust, mutual respect, responsibility, commitment, solidarity and initiative) and on the other, the Global and critical vision of environmental issues and the promotion of an interdisciplinary approach that will rescue and build knowledge.

When we refer to environmental education, we place it in a broader context, that of education for citizenship, configuring it as a determinant element for the consolidation of citizen subjects. The challenge of strengthening citizenship for the population as a whole, not for a restricted group, is achieved by the possibility of each person being a bearer of rights and duties, and of becoming a co-responsible actor in the defense of quality of life. When talking about Sustainable Education, one is talking about not just one type of knowledge. Environmental Education, in turn, talks about social representation, for the conquest of citizenship. It does not refer only to the environment as many people think; Today, implies the attempt to change the anthropocentric thought of man to show that he is part of nature and therefore has to obey ecological principles and diversity. It is necessary that in the educational media can be incorporated the diversity of social policies and practices as a subsidy in the learning teaching process, stimulating teachers and students to the commitment and ethical sense to ecological practices aimed at environmental preservation, as well as the awakening to very simple things that can be done to reduce the impact to the environment through practical attitudes towards the three $\mathrm{R}$ 's of conscious consumption are: reduce, reuse and recycle. From experience as a teacher it is realized that much can be done in this aspect in the sense that it can involve every school community by raising awareness of the need for conscious actions and responding positively to the demands of sustainability, in firm and systematic actions in the treatment with the environment.

If there are a number of problems relating to the environment, this is partly because people are not sensitized to understanding the fragile balance of the biosphere and the problems of natural resource management. They are not and have not been prepared to delimit and effectively solve the concrete problems of their immediate environment, because education for the environment as a didactic or pedagogical approach only appears in the 1980s. The possibility of becoming aware of situations that cause problems in their immediate environment or the biosphere in general, reflecting on their causes and determining the appropriate means or actions in an attempt to solve them. 


\section{Some Considerations: Away from Conclusion}

The arguments presented in this article do not pretend to exhaust the theme presented given the complexity of it. Much still exists to be done, because cartography, interdisciplinarity, cultural knowledge, all in harmony seek to contribute to the understanding of environmental education, as a new instrument still in the Brazilian educational foundations, while we know that only the process Educational system can not account for all the resolutions to the broad problems faced, thus, it is necessary to harmonize between cultural knowledge and interdisciplinary interdisciplinarity as complementary factors, in the search for ways to the understanding of individuals in the construction of the exercise of citizenship.

Therefore, this article expresses the desire to aggregate values, inasmuch as they propose to take into account multicultural, transdisciplinary and ethical elements in national environmental education.

Since this is a theoretical contribution, the present research suggests the need to deepen and debate the theme in an attempt to broaden studies, research and, of course, create new methodological approaches within more modern conceptions aimed at the revision of environmental education projects, for those who know to elaborate more effective plans in this area, with practices and discussions still insipient in our country. It is fundamental that we build a democratic process of access to public environmental education policies, as well as, citizen networks as a way of inserting more and more individuals within this still diffused everyday life in a society that commits day by day with international agreements and commitments For social and environmental policies, but still has serious problems of substantial investments in educational development, as well as in the qualification of serious public policies, as tools necessary to reconcile theoretical discourses with true eco-social practices, bringing the dance The subjects of education in the broadest sense, the plural subject.

\section{References}

[1] Fazenda, I. C. A. [org.], Methodology of educational research, Cortez, São Paulo, 1993.

[2] Fazenda, I. C. A, Interdisciplinarity and Transdisciplinarity: in teacher training, PUCSP, 2000.

[3] Moraes, A, EC $n^{\circ}$ 67/10 e Súmula vinculante 31. [32a ed], Imprenta, São Paulo, 1988.

[4] Foucault, M, Microphysics of power, [organization and translation of Robert Machado], Graal, Rio de Janeiro, 1979.

[5] Deleuze, G. and Guattari, F, Thousand plateaus. Capitalism and schizophrenia, (translation Peter Pál Pelbart and Janice Caiafa], Publisher 34, São Paulo, 1995.

[6] Kastrup, V, The functioning of attention in the work of the cartographer, Psychology and Society, Porto Alegre, 19(1). Jan./Abr. 2007.

[7] Deleuze, G, Conversations, [translation Peter Pál Pelbart], Publisher 34, São Paulo, 1996.

[8] Simondon, G, L'individu et sa genèse psysico-biologique, Presses Universitaires de France, Paris, 1964.

[9] Callai, H. Study the place to understand the world, in Castrogiovanni, A. C. [org.], Teaching geography: practices and textualizations in everyday life, Mediation, Porto Alegre, 2005.

[10] Japiassu, H, Interdisciplinarity and pathology of knowledge, Imago, Rio de Janeiro, 1976.

[11] Sorrentino, M, From Tbilisi to Tessaloniki, environmental education in Brazil, Environmental Review, Oct. 1998. 